\title{
Escolas de governo européias reformam o ensino e voltam-se à Europa*
}

Por Claudia Asazu

As principais escolas nacionais de governo da Europa encontram-se hoje em processo de transformação. Nas agendas de mudança, ressaltam-se a "europeização" da formação e o reforço no ensino de liderança.

É o caso da ENA - Ecole Nationale d'Administration, que oferece cursos de formação inicial e continuada aos servidores que compõem a chamada "alta função pública” da França. As críticas lançadas à tradicional escola - "francesa, parisiense, tecnocrática e elitista demais" tiveram impacto no resultado da reforma. Um terço do período de formação inicial passou a ser dedicado ao estudo da Europa, o campus foi transferido de Paris a Strasbourg, a formação teórica é hoje alternada com a realização de estágios e os concursos passaram a ser abertos a um público não apenas puramente acadêmico.

No Reino Unido, a antiga Civil Service College, criada em 1970, renasceu em 2005 como National School of Government, com um novo modelo de oferta de soluções de formação, centrado na identificação "individualizada" das demandas de ministérios e agências e no treinamento customizado. A escola britânica, nesse sentido, atua hoje mais propriamente como consultora e intermediadora de formação do que ofertante de cursos.

A BaköV - Academia Federal de Administração Pública, da Alemanha, vem ancorando sua formação no "servidor motivado", um dos alicerces da reforma da administração pública em curso no país desde 2004. Confere destaque, nessa linha, aos cursos de desenvolvimento de pessoal e de liderança dentro do "Quadro Comum de Competências" dos servidores públicos, elaborado a partir da pergunta: "Quais os conhecimentos, as habilidades e as atitudes necessárias para que um servidor em posição de liderança seja bem sucedido na arena européia?".

A EIPA - European Institute of Public Administration, por sua vez, financiada pelos Estados-membros da União Européia e pela Comissão Européia, propõe complementar a formação das respectivas escolas nacionais estabelecendo-se como escola "verdadeiramente européia".

Leia, a seguir, um pouco mais sobre a atuação dessas escolas.

\section{ENA - Ecole Nationale d'Administration - França}

Criada no fim da $2^{\text {a }}$ Guerra com o objetivo de democratizar o recrutamento de dirigentes do Estado, a ENA completou 60 anos em 2005 em meio a um processo de deslocalização e de implementação de nova proposta curricular para os cursos de formação inicial e continuada. 
"As críticas lançadas ao governo são também lançadas à ENA", diz Françoise Camet, diretora de Formação Continuada e de Pesquisa, fazendo uma análise das mudanças em curso. O 'não' ao anteprojeto de constituição da UE [no referendo realizado em maio de 2005], a crise nos subúrbios (banlieus) das grandes cidades francesas [em novembro de 2005] e a rejeição à proposta governamental de Contrato de Primeiro Emprego [Contrat premier embauche, CPE, que desencadeou manifestações em março e maio de 2006] nos obriga a rever os aspectos fundamentais da função pública”, ressalta.

A formação inicial foi dividida em duas fases. A primeira delas, de 24 meses, alterna ensino e estágios e busca reforçar o caráter de "escola de aplicação". "A ENA não é uma universidade. Não se trata de oferecer um ensino teórico ou acadêmico, mas de formar 'práticos', já que os alunos já possuem formação acadêmica", ressalta Christian Saves, diretor-adjunto de Estudos.

A primeira fase é composta de três módulos - Europa, Territórios e Gestão e Gerenciamento Públicos. O módulo Europa foi estendido e dura atualmente 28 semanas. Após uma preparação ao estágio de três semanas, incluindo cursos sobre instituições européias e exercícios de comunicação e negociação, os alunos partem para um estágio de 17 semanas em uma instituição européia ou internacional.

O módulo Territórios, que se concentra no aprendizado das especificidades da administração territorial e das coletividades locais, é realizado em conjunto com o INET - Institut National des Etudes Territoriales, responsável pela formação dos quadros superiores da função pública territorial, que trabalham nas coletividades locais. Os alunos da ENA compartilham o curso com os alunos do instituto durante todo o módulo. Uma fase preparatória de três semanas, com exercícios de comunicação de crises, media training e negociação, além da preparação de um projeto que associe o Estado e a coletividade, precede o estágio de 22 semanas em uma préfecture ou uma coletividade territorial.

O último módulo, Gestão e Gerenciamento Públicos, é composto de dois estágios. Os alunos trabalham dez semanas em uma empresa, centrando o aprendizado na questão do desempenho (gestão de equipes, projetos, avaliação, etc.). Esse estágio é precedido de uma semana de cursos de direito privado, de análise das especificidades da gestão dos recursos humanos no setor privado e de questões

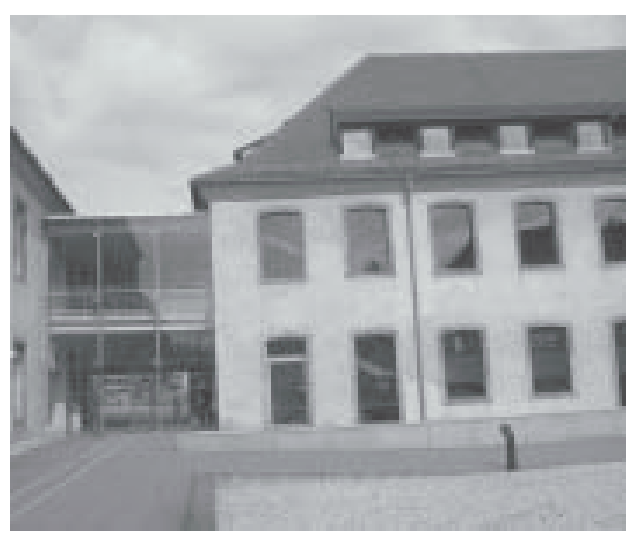

O campus da ENA em Strasbourg: prisão feminina transformada em escola

econômicas. Em seguida, os alunos partem para um último estágio, de quatro semanas de duração, em algum ministério localizado em Paris.

A segunda fase da formação, de três meses, é de aprofundamento, em formato de "mini-seminários" geridos pelos próprios alunos. Em grupos de cinco ou seis, os alunos podem escolher uma área (questões jurídicas, políticas sociais, decisão econômica, problemáticas orçamentárias e financeiras, problemáticas territoriais e cooperação internacional). Exige-se deles a elaboração coletiva de uma dissertação, avaliada por um júri. 
A escola não mantém um corpo permanente de professores. "Os instrutores são, na maioria, servidores de alto escalão com comprovada experiência. Pedimos para que transmitam a realidade da administração pública de maneira concreta, com base em casos práticos e na utilização de dossiês de casos reais" diz Christian Saves.

O campus principal da ENA, que durante 60 anos funcionou em Paris, foi transferido para Strasbourg, a $500 \mathrm{~km} \mathrm{da}$ capital. O local pertencia à Ordem de São João de Jerusalém, e as construções mais antigas datam do século XIII. Serviu, até 1988, como cadeia feminina. Para transformar-se em escola, foi necessária uma operação imobiliária e arquitetônica que levou 12 anos para ser concluída. O curso de formação, dividido entre Paris e Strasbourg, passou a ser definitivamente concentrado em Strasbourg a partir de 2005.

\section{Gestão e avaliação de competências}

A partir de 2006, a ENA põe em prática uma nova dinâmica de gestão prévia de carreiras, com a elaboração de um levantamento de competências individualizado. Essa análise leva em conta os conhecimentos e as competências que os alunos deverão, ao fim do curso, ter adquirido, bem como as aptidões individuais como a escuta, o senso crítico, a capacidade de negociação, de comunicação, de motivação, entre outros.

O levantamento procura orientar a escolha da carreira e traçar um percurso profissional que seja mais bem adaptado à personalidade, às necessidades e às ambições de cada aluno. A primeira avaliação é feita no início do curso de formação e mede, por meio de testes de múltipla escolha, os conhecimentos nas áreas de direito, finanças públicas, economia, território, Europa, gestão e gerenciamento públicos. No meio do curso, nova avaliação irá medir conhecimentos e competências específicos sobre gestão e gerenciamento no setor público. O terceiro levantamento é feito pouco antes da partida dos alunos e avalia tanto os conhecimentos, por meio de testes, quanto as aptidões, por meio de testes e entrevistas com consultores externos. Os levantamentos são pessoais, confidenciais e não influem na nota final. O último deles, entretanto, poderá ser encaminhado ao órgão no qual o aluno foi lotado.

Terminado o curso, a primeira alocação resulta de um processo de discussão entre o ministério ou corps e o aluno, levando-se em conta o perfil do aluno e do posto desejado.

Uma vez alocado, o servidor deve permanecer no posto por um período mínimo de dois anos. Depois desse prazo, inicia-se o período chamado de "mobilidade estatutária", no qual os servidores devem escolher um posto em outro ministério, em alguma empresa ou em instituições européias ou internacionais. Essa mobilidade é obrigatória e é prorrogável.

\section{Pólo europeu}

O conjunto arquitetônico do campus de Strasbourg engloba também o Centro de Estudos Europeus de Strasbourg (CEES), que passou a ser juridicamente vinculado à ENA em 2005 e constitui o pólo europeu da escola. Ele atua como apoio no estudo, concepção e operacionalização de cursos especificamente voltados a questões européias. Eles são, em grande parte, de curtíssima duração (um ou dois dias) e destinados a parlamentares, dirigentes e servidores públicos, além de executivos do setor privado, franceses e estrangeiros.

Todos os cursos são sob medida. "Não trabalhamos com catálogo de forma 
a garantir a flexibilidade e atender a diferentes demandas", diz Dorothée Meyer, coordenadora pedagógica do centro. Há três grandes categorias de temas - políticas européias, ação da UE no exterior e questões institucionais - que se desdobram, por exemplo, em cursos como "A fraude orçamentária na UE", "A política européia de segurança e defesa" e "O lobby nas instituições européias: modo de usar".

Outra atividade importante do CEES é a preparação de candidatos aos concursos de seleção das instituições européias. Uma das metas é aumentar o número de funcionários franceses nos órgãos da UE. "A participação francesa nas instituições da UE vem regredindo", afirma Meyer. No entanto, boa parte dos cursos é oferecida a estrangeiros, principalmente àqueles provenientes dos países recém-incorporados no bloco. Segundo ela, $50 \%$ das atividades do centro são voltadas para eles. Em 2005, o centro organizou 87 cursos preparatórios para 3,7 mil candidatos. O CEES mantém também uma revista online, disponível em www.etudes-europeennes.fr.

\section{Pees'-
Préparation aux concours
des institutions européennes}

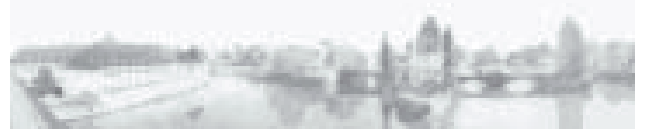

Informativo da CEES sobre concursos nas instituições européias

\section{Convocação obrigatória}

Entre os cursos de formação continuada na ENA, destacam-se os seminários de gerência para diretores e vice-diretores recém-empossados nas administrações centrais. O curso existe desde 2004, e a participação é obrigatória.

"Telefonamos aos diretores e vices para confirmar a participação. Eles, inclusive, recebem um ofício do secretário-geral do governo convocando-os para os seminários", explica Lucile DromerNorth, coordenadora dos cursos de curta duração. "Muitos vêm a contragosto, mas partem contentes", garante.

As palestras são conduzidas por dirigentes do setor público e privado e tratam de temas como planejamento estratégico, mobilização de equipes, gestão do tempo, condução de mudanças, entre outros.

No INET, são organizados seminários denominados "ciclos estruturantes", dirigidos aos diretores-gerais e diretoresadjuntos das coletividades territoriais em diferentes momentos de suas carreiras. As discussões se pautam em torno de temas como os novos desafios gerenciais, organização, condução e avaliação de políticas públicas, oportunidades e desafios da descentralização, entre outros. São oferecidos oito módulos ao longo do ano, cada qual com dois dias e meio de duração. "A idéia é fazer com que eles confrontem suas experiências com as de colegas do mesmo nível. É um momento de levantar a cabeça do guidão e procurar ver além", diz JeanMichel Delaye, responsável pela formação continuada de dirigentes no instituito, fazendo uma alusão ciclística.

Os ciclos incluem viagens de estudos ao exterior para comparar diferentes realidades administrativas. "Queremos que nossos dirigentes vejam que, em outros países, servidores executam, às vezes, os 


\section{A função pública francesa e as carreiras dos “enarcas"}

$\mathrm{Na}$ França, existem três grandes funções públicas: a função pública do Estado, a função pública territorial e a função pública hospitalar, nas quais atuam cinco milhões de servidores. A ENA forma os futuros dirigentes e detentores de altos cargos da função pública do Estado, enquanto ao INET cabe a formação dos dirigentes da função pública territorial. Para a ENA, os candidatos são recrutados por meio de: concurso externo (com limite de idade de 28 anos), concurso interno (aberto aos servidores públicos de outros níveis com pelo menos quatro anos na função pública e com até 45 anos) e terceiro concurso (aos profissionais do setor privado com oito anos ou mais de atividade profissional ou de exercício de mandato político ou sindical). Há, anualmente, em torno de 90 vagas para esses três concursos. Desde 2004, é aberto também aos cidadãos provenientes da União Européia.

A partir da admissão, os alunos tornam-se servidores-estagiários e são remunerados pelo Estado. Ao final do curso de formação, assumem o compromisso de trabalhar para o Estado por um período mínimo de dez anos.

Os "enarcas" podem optar, como primeira lotação, pelo posto de administrador civil (administrateur civil) nos diferentes ministérios; de inspetor (inspecteur adjoint) nos órgãos de controle da atividade pública (Inspection Generale); de auditor/conselheiro no Conselho do Estado (Conseil d'Etat), no Tribunal de Contas (Cour des Comptes) ou no Tribunal Administrativo; de chefe de gabinete do préfet ou de seu vice; e, por fim, de conselheiro do Ministério dos Negócios Estrangeiros, se desejar seguir carreira na diplomacia. Os cargos mais concorridos estão: no chamado grand corps: Conseil d'Etat (Conselho do Estado), Cours de Compte (Tribunal de Contas) e Inspection Générale des Finances (Controladoria Geral das Finanças); no Ministério da Economia, Finanças e Indústria; nas préfectures (representação do Estado nos departamentos) e na diplomacia.

Fontes: ENA (www.ena.fr), Direction Générale de l'Administration et de la Fonction Publique (www.fonction-publique.gouv.fr)

mesmos trabalhos com equipes de cinco ou seis pessoas, quando nós contamos com equipes de 50”, diz. Em 2006, um grupo esteve no Rio de Janeiro e em Belém.

$\mathrm{O}$ instituto oferece também o bilan management (avaliação de gerenciamento), um dispositivo de acompanhamento dos quadros de direção da função pública territorial. "Essa avaliação tem caráter intimista, é centrado na pessoa e não no conhecimento", explica Maxence Chorvot, que coordena esse evento. Os grupos são de em torno de 15 pessoas, de, em média, 45 anos, que se reúnem por oito dias ao longo de dois meses. "É essencial que a participação seja voluntária. Os dirigentes têm de baixar suas defesas, falar francamente". Não se trata, porém, ressalta
Chorvot, de uma "terapia de grupo". A avaliação tem como objetivo de elaborar um projeto de evolução profissional e identificar os meios necessários para garanti-la. Ela procura responder a algumas perguntas como: "quais são as minhas práticas gerenciais?”, "como me posicionar e evoluir em meu ambiente profissional?”, "como inserir-me em uma dinâmica professional correspondente às minhas motivações, valores e competências?”.

\section{National School of Government - Reino Unido}

$\mathrm{Na}$ escola de governo do Reino Unido, as mudanças começaram a ser implementadas em 2005, quando a Civil Service College, criada em 1970, foi 
rebatizada de National School of Government e adquiriu status de "departamento não-ministerial".

As diretrizes da escola passaram a ser fixadas pelo conselho de administração, formado por 12 representantes do governo, do setor privado e do terceiro setor. Cinco deles são secretários permanentes (ministros) de áreas estratégicas do governo.

A maneira pela qual a escola se relaciona com o seu público também mudou. "A nossa linha de frente, que até então era o catálogo de cursos, passou a

\section{Relatórios marcam as grandes reformas do serviço público britânico}

"A admissão ao serviço público é, de fato, algo fortemente desejado, mas por aqueles que têm pouca ou nenhuma ambição, indolentes e incapazes... são colocados no serviço público, onde obtêm um meio de vida honroso com pouco trabalho e sem risco, onde seu sucesso depende simplesmente de evitar erros flagrantes de conduta e cumprir, com moderada regularidade, as tarefas rotineiras...". Assim era descrito o funcionalismo público do Reino Unido no relatório Northcote-Trevelyan, de 1854, que serviu de base para o processo inicial de profissionalização do serviço público naquele país.

O relatório recomendava um sistema adequado de concurso antes da nomeação e de transferências entre departamentos, promoção por mérito rigorosamente supervisionada e aumentos salariais condicionados à realização de trabalho satisfatório, que passaram, gradualmente, a serem adotados.

Em 1968, foi publicado o Relatório Fulton, que lançou alicerces para a segunda grande reforma do serviço público britânico. A percepção de lorde Fulton era de que o serviço civil era "essencialmente baseado no culto ao amador ou ao generalista", integrado por "muitos cientistas, engenheiros e outros especialistas aos quais não lhes são atribuídos a responsabilidade e autoridade que merecem" e formado por pessoas que não tinham formação profissional específica ou treinamento formal para desempenhar seus trabalhos.
Howard Emmens, professor da National School e servidor público há 40 anos, lembra-se desse período. "Quando entrei no serviço público, tínhamos apenas um 'curso' de um dia, que nos mostrava onde era a cozinha, nos alertava para não chegar atrasados, etc".

O relatório Fulton apontava que o serviço civil, além disso, carecia de gerentes competentes. Era preciso, portanto, aperfeiçoar as competências gerenciais - os administradores deveriam especializar-se e cientistas e especialistas deveriam receber treinamento em gerenciamento. Recomendava, assim, entre outros, a criação de um Departamento (ministério) do Serviço Civil para dirigir o serviço público (o que era, até então, realizado pelo Departamento do Tesouro) e a criação de uma Escola do Serviço Civil (Civil Service College). Antecessor da National School of Government, o Civil Service College foi inaugurado em 1970.

Essas diretrizes, no entanto, mudaram com o governo Thatcher. O Departamento do Serviço Civil foi extinto e o Civil Service College foi transformado em agência executiva. "O departamento foi uma das primeiras baixas do período Thatcher", diz Howard Emmens. "E a escola passou a ser um órgão que poderia continuar a existir contanto que não custasse muito aos cofres públicos. A visão era de que ela deveria oferecer treinamento de catálogo em grande escala. O foco era sobre nós mesmos, os ofertantes". O status de agência executiva da escola durou até 1999.

Fonte: www.civilservice.gov.uk 
ser nosso time de gerentes de relacionamento estratégico (strategic relationship managers)", explica David Spencer, reitor e executivo-chefe da National School.

Para atender as solicitações de curso caso a caso, cada gerente tem um portfólio de departamentos (ministérios) e agências e age como seu ponto focal dentro da escola, identificando suas demandas e necessidades. Feito isso, a escola determina se o curso pode ser dado por ela própria, pelas organizações parceiras, que incluem universidades britânicas e estrangeiras, ou se deve recomendar terceiros. Os gerentes também discutem com os departamentos qual a melhor estratégia de divulgação. "Não estamos no ramo de confecção de roupas, mas fazemos tudo sob medida e com ajustes", diz Bob MacLennan, chefe de Planejamento Estratégico, definindo o novo perfil da escola.

"Queremos, assim, que a busca pelos cursos deixe de ser individual, via catálogo, e passe a ser institucional", afirma Spencer.

\section{britânico \\ “Think tank" do serviço público}

Um importante braço da National School é o Instituto Sunningdale, um espaço acadêmico virtual que congrega 40 acadêmicos britânicos, europeus e norteamericanos, com experiência acadêmica e prática no setor público, entre os quais estão professores da Universidade de Harvard, da London School of Economics e da Stockholm School of Economics.

O instituto constitui um "think tank" da administração pública britânica, criado para pesquisar e propor soluções inovadoras aos problemas do setor público. Seus acadêmicos, em grupos ou individualmente, podem atuar com determinado departamento prestando consultoria, liderando projetos, produzindo documentos técnicos ou dando palestras.
A National School também conta com 500 professores associados. Há grande ênfase em cursos de liderança para dirigentes, destacando-se o Top Management Programme. Em um curso intensivo de 20 dias, os participantes discutem temas como liderança pessoal e organizacional, condução de mudanças, gestão de riscos e crises, comunicação efetiva dentro e fora da organização, entre outros. Propõe-se, durante o curso, que os dirigentes atuem como consultores para uma organização com problemas dessa natureza. Em uma de suas edições, por exemplo, incluiu-se a elaboração de um projeto à Secretaria de

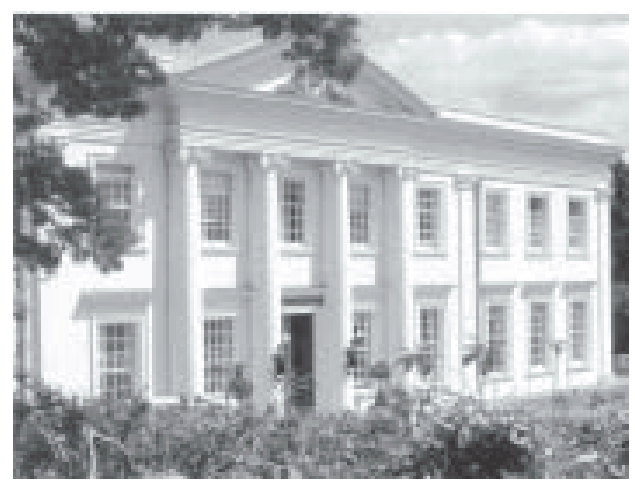

Instituto Sunningdale, o espaço acadêmico virtual da National School of Government

Imigração e Nacionalidade, que estava preocupada com a sua reputação perante a mídia, grupos de lobbys e imigrantes.

Também nessa linha, uma gama de cursos e eventos é voltada para os membros dos conselhos de administração de departamentos e agências governamentais, como o Board effectiveness and corporate leadership programme (programa de liderança corporativa e efetividade do conselho). Existem, ainda, eventos específicos para os chamados conselheiros não-executivos (non-executive board members), que não têm vínculo direto com o departamento ou agência, mas são chamados a integrar o seu conselho e têm poder de decisão nele. É o caso da rede 
de conselheiros não-executivos e da Conferência Anual dos Conselheiros NãoExecutivos, que reúne dirigentes de empresas públicas e privadas e conselheiros para compartilhamento de experiências e avaliação de seus desempenhos. "É uma estratégia não invasiva para fazer com que os dirigentes discutam o que está ocorrendo nos departamentos. As conferências ocorrem em clima bastante informal e muitas das questões levantadas ali são confidenciais", diz Sai Shanmugarajah, um dos responsáveis pelos "non-execs".

Ênfase é dada também para as questões européias: cursos de negociação na UE, que preparam servidores a presidirem mesas de reuniões em Bruxelas, e visitas de estudos a Bruxelas e Luxemburgo, entre outros, fazem parte do programa europeu da escola.

Os integrantes do "fast stream" - porta de entrada para as carreiras gerenciais do serviço civil britânico aos que têm formação universitária de pelo menos quatro anos também recebem formação específica, com cursos como "Desenvolvimento de carreira para gerentes mulheres" e "EU para os fast stream", ambos de dois dias.

Grande parte dos cursos, por sinal, tem curta duração (dois ou três dias). "Treinamento hoje em dia é um luxo porque a rotina dos servidores não lhes possibilita ausências prolongadas. Em 1979, eu fiz um curso de formação de quatro semanas na Civil Service College. Não há mais cursos com essa duração hoje", diz Howard Emmens, que integrou o serviço público britânico há 40 anos e hoje coordena os cursos de UE.

\section{BaköV - Academia Federal de Administração Pública - Alemanha}

Motivar o servidor público e torná-lo apto a enfrentar um cenário econômico e social em transformação. Essa é uma das missões atribuídas à BaköV no processo de reforma da administração federal em curso na Alemanha.

O cenário, mostra Hans-Edmund Kunsmann, professor e diretor de Relações Internacionais e Gestão de Recursos Humanos da BaköV, é desafiador, tendo em vista a crise financeira estrutural - o país não vem conseguindo atingir as metas de estabilidade fiscal da UE há quatro anos -, o envelhecimento populacional e a expansão

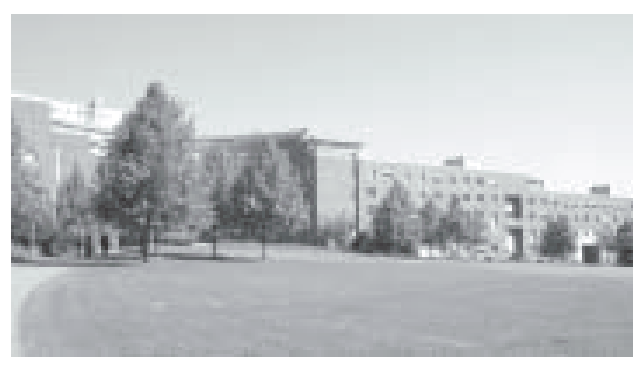

O amplo campus da BaköV em Brühl

do bloco, que aumenta a complexidade da tomada de decisões políticas.

O "servidor motivado" é um dos alicerces da reforma. "Fizemos um levantamento das tentativas de modernização do serviço público e concluímos que $70 \%$ dos projetos fracassaram porque não levaram em conta o fator humano. A modernização que propomos hoje é vinculada às pessoas, às competências críticas e soft skills [competências nãotécnicas] necessárias e não tanto aos instrumentos", explica Kunsmann.

Assim, ao lado de cursos de aperfeiçoamento em orçamento, organização e planejamento, tecnologia da informação, legislação, etc., uma gama de cursos é voltada para o desenvolvimento de pessoal, destinados principalmente a dirigentes.

Um exemplo é o ensino de liderança. A escola adotou, a essa temática, uma nova 
abordagem metodológica, baseada no "Quadro Comum de Competências". O quadro é resultado de uma pesquisa realizada com 25 institutos de administração pública européias, partindo do pressuposto que, em uma UE maior, seriam necessárias competências diferentes daquelas utilizadas em contexto unicamente nacional.
As competências a serem citadas deveriam procurar responder à questão: "O que um servidor público em posição de liderança necessita conhecer [conhecimento], fazer [habilidades] e mostrar [atitudes] para ser bem sucedido na arena européia?".

Os resultados foram agrupados em dois modelos:

\section{Modelo 1: Resultados por clusters de competências}

\begin{tabular}{|l|l|l|}
\hline Atitudes & Habilidades & Conhecimentos \\
\hline $\begin{array}{l}\text { "Mente aberta" } \\
\text { - flexibilidade }\end{array}$ & $\begin{array}{l}\text { Sociais } \\
\bullet \text { habilidade para ouvir } \\
\bullet \text { habilidades interculturais } \\
\bullet \text { habilidades comunicativas }\end{array}$ & $\begin{array}{l}\text { Em nível europeu } \\
\bullet \text { das instituições } \\
\bullet \text { dos procedimentos } \\
\bullet \text { das políticas da UE }\end{array}$ \\
\hline $\begin{array}{l}\text { Inovadoras } \\
\bullet \text { proatividade } \\
\bullet \text { coragem }\end{array}$ & $\begin{array}{l}\text { Relacionais (networking) } \\
\bullet \text { habilidade para construir } \\
\text { consenso }\end{array}$ & $\begin{array}{l}\text { Em nível nacional } \\
\bullet \text { de políticas setoriais } \\
\bullet \text { dos grandes sistemas e } \\
\text { das prioridades }\end{array}$ \\
\hline $\begin{array}{l}\text { Íntegras } \\
\bullet \text { honestidade }\end{array}$ & $\begin{array}{l}\text { Negociais } \\
\bullet \text { habilidades de negociação }\end{array}$ & $\begin{array}{l}\text { Relacionais } \\
\bullet \text { das redes sociais }\end{array}$ \\
\hline & Orientadas para resultados & \\
\hline & Organizacionais & \\
\hline
\end{tabular}

Fonte: BaköV

\section{Modelo 2: Resultados por freqüência de citação}

As dez competêcias mais mencionadas (54\%) de um total de 42

- Habilidades negociais

- Conhecimento dos procedimentos

- Conhecimento das instituições

- "Mente aberta"

- Perspectiva estratégica

- Habilidades sociais

- Habilidades relacionais (networking)

- Habilidades organizacionais

- Comunicação intercultural

- Integridade

Fonte: BaköV 


\section{Ensino procura combinar presencial e e-learning}

A BaköV oferece cursos de educação a distância (EAD) desde 1998. O formato mais bem-sucedido de ensino, explica Udo Heyder, diretor da área de e-learning e novas mídias, combina as modalidades presencial e a distancia.

Os cursos de EAD são oferecidos como revisão e aprofundamento do curso presencial ou como fonte de consulta posterior. Em alguns casos, servem também para introduzir o tema antes do curso presencial.

Outra linha de cursos são os programas "passo-a-passo". Um deles, por exemplo, ensina como se elaboram as leis, mostrando todas as fases do processo e trazendo, ainda, estudos de casos específicos e experiências bem-sucedidas com a utilização dos procedimentos ensinados. "Procuramos contribuir, assim, para a padronização de procedimentos", afirma Heyder.

Existem hoje 25 programas de e-learning, dos quais 15 são de produção própria. "Optamos por produzir nós mesmos os programas para assegurar que os conteúdos tragam a didática e os valores da academia", diz.

Heyder ressalta que há um mito de que o e-learning gera economia de custos e de tempo. "Mas isso, de fato, é um mito", observa. Na BaköV, um professor ou servidor experiente elabora um script do curso de EAD e a escola oferece o apoio técnico. Trata-se, porém, de um produto que demanda muito investimento. Heyder faz os cálculos: o desenvolvimento de programas de EAD custa, em média de 20 mil a 40 mil euros, o mesmo custo, por exemplo, de 100 seminários. O tempo de aprendizado gasto na EAD, além disso, é quase o mesmo dos cursos presenciais. "Nesse sentido, as vantagens dessa modalidade têm de ser em termos de aprendizado", afirma.
Uma das principais metas da academia é, desta forma, aumentar a inserção alemã na União Européia ampliada.

A BaköV está atenta também para as mudanças culturais. "Antes, na cultura alemã, o cidadão que necessitava de um serviço público tinha quase que implorar para ser atendido. Isso era aceitável. Hoje, o cidadão espera que o atendimento seja excelente como no setor privado e temos que trabalhar com essa realidade", diz Kunsmann.

Vinculada ao Ministério do Interior e com sede em Brühl (localizada entre Colônia e Bonn), a academia atende 13 dos 15 ministérios que compõem a administração pública federal alemã, um universo de 300 mil servidores.

O amplo conjunto arquitetônico inclui alojamento com capacidade para 450 pessoas. Obras de arte estão espalhadas por todas as dependências. "É que as construções públicas devem destinar uma parte do orçamento para obras de arte", explica o professor.

\section{EIPA - European Institute of Public Administration - Holanda}

"À primeira vista, concorremos com as escolas nacionais de governo. $\mathrm{Na}$ verdade, porém, somos mais propriamente um suplemento", define Tore Malterud, chefe da Unidade de Gestão Pública do Instituto Europeu de Administração Pública, que se dedica à formação de servidores dos Estados-membros da UE e à pesquisa aplicada em administração e políticas públicas européias.

Criada em 1981, a proposta da EIPA é ser "verdadeiramente européia". "Nosso valor agregado é a possibilidade de intercâmbio entre as várias escolas nacionais", explica Malterud. O instituto tem hoje cerca de 110 funcionários, entre a equipe permanente, os funcionários contratados 


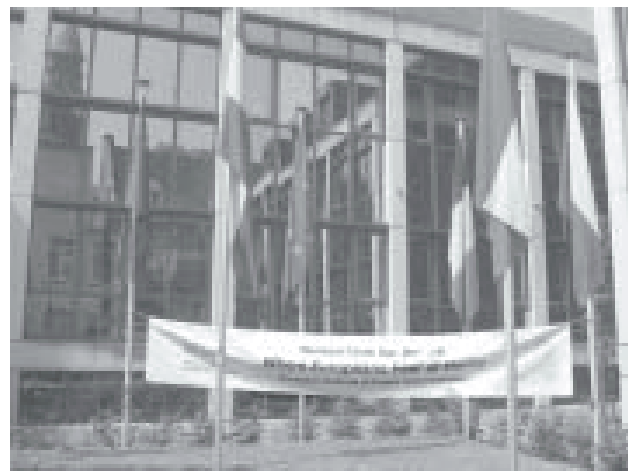

EIPA: "Onde europeus sentem-se em casa"

(de um a três anos) e os recrutados de cada um dos Estados-membros (os chamados seconded), servindo de ponto de contato entre o instituto e o país. Todos devem realizar pesquisa, consultoria e treinamento.

A EIPA é financiada pelos governos dos Estados-membros do bloco, pela Comissão Européia - é uma rubrica do orçamento da comissão - e pelos países associados (candidatos e futuros candidatos à União Européia).

Trabalha tanto com atividades abertas - seminários como "Política ambiental na EU: como entender a Política de Águas" ou "Direito da UE para não-advogados" - como com cursos sob medida.

É dividida em três unidades. A de Tomada de decisão na Europa promove eventos sobre os processos decisórios nas instituições da UE, sobre negociação e sobre os comitês e a comitologia, ou seja, os procedimentos a serem seguidos pelos vários comitês que compõem a Comissão Européia, instância responsável pela implementação da legislação comunitária. Realiza, ainda, seminários que preparam países para ocupar a presidência do bloco. A segunda unidade organiza eventos e pesquisa sobre Gestão Pública e Administração Pública Comparada e a terceira dedica-se a Políticas Européias.

O instituto tem, ainda, filiais (chamadas de "antenas") em Barcelona (especializada em questões regionais), em Luxemburgo (dedicado a juízes e advogados), em Milão (que trata de questões sociais e da atenção pública à saúde) e em Varsóvia (especializada em gestão das finanças públicas).

A EIPA também alimenta banco de dados e fóruns de discussão sobre tópicos específicos como a Política Comum Externa e de Segurança, Gestão da Informação e Comunicação na Europa, Parceria público-privada na Europa e Compras Governamentais.

\section{Benchmarking}

Uma série de projetos liderados pelo instituto busca facilitar o benchmarking (estudo comparativo e intercâmbio de boas práticas) entre os países da UE. Um dos exemplos é o estabelecimento de um Quadro Comum de Avaliação (Common Assessment Framework, CAF) de órgãos públicos da União Européia.

O CAF é um modelo de avaliação que busca ajudar organizações públicas a utilizar técnicas de gestão total da qualidade para melhorar seus desempenhos. Um de seus diferenciais é a possibilidade de autoavaliação. A EIPA é, desde 2001, o centro de inteligência em CAF.

Outro projeto do instituto é o eEurope Awards, um concurso que premia práticas inovadoras em governo eletrônico e na implementação de tecnologias de informação na área de saúde nos paísesmembros da UE. Um banco de dados de boas práticas européias está disponível em www.egov-goodpractice.org.

\footnotetext{
* O artigo é resultado da missão técnica, composta por servidoras da ENAP, a instituições congêneres européias. Realizada entre 8 e 19 de maio de 2006, a missão foi financiada pelo Projeto EuroBrasil 2000 - Apoio à Modernização do Aparelho do Estado, cooperação técnica firmada entre a Comissão da União Européia e a Secretaria de Gestão do Ministério do Planejamento, Orçamento e Gestão.
} 